\title{
Potential years of life lost: what is the denominator?
}

\author{
Andrea K Marlow
}

\begin{abstract}
Objective - To suggest an appropriate denominator for use with the statistic "potential years of life lost", in order to facilitate valid comparisons between health authorities.

Design - Analysis of OPCS population and mortality data for the period 1987-91.

Setting - Data for Wales were analysed to provide comparisons between the nine district health authorities.

Subjects - There were 46139 males and 30258 females - that is, all deaths of Welsh residents, aged under 75 years, during the period 1987-91.

Main results - The use of age sensitive denominators with the potential years of life lost statistic alters the rank position of Welsh district health authorities.

Conclusion - It is suggested that potential years of life lost should be expressed as a rate per 100000 potential years of life in public health common data sets, and elsewhere, to facilitate valid comparisons between health authorities.
\end{abstract}

(f Epidemiol Community Health 1995;49:320-323)

The calculation of potential years of life lost is one of many measures used by epidemiologists to assess the health status of populations. The statistic measures the total number of life years lost due to premature death. The choice of the definition of premature death is arbitrary, though Ortega and Puig ${ }^{1}$ have argued that the use of 65,70 , or 75 years could influence the relative importance assigned to different causes of premature death.

The Department of Health public health common data set for $1991^{2}$ and the Welsh public health common data set $1987-91^{3}$ both include average annual years of life lost for selected causes of death. Both data sets chose deaths under 75 years as being premature; the same definition has been used in this paper. The actual methodology for deriving years of life lost (YLL) is as follows:

$$
\mathrm{YLL}=\Sigma(74 \cdot 5-\mathrm{y}) * \mathrm{~N}_{\mathrm{y}}
$$

Public Health

Department of Public

Health Medicine,

Powys Health,

The Laurels,

Bronllys, Brecon,

Powys LD3 0HS

A K Marlow

Correspondence to: Mrs A K Marlow.

Accepted for publication September 1994 sets moves away from this concept and more towards YLL comparisons between populations and in particular between district health authorities (DHAs). Clearly, in order to achieve these comparisons a denominator is required The point for consideration in this paper is what the denominator should be.

Both the Department of Health and the Welsh Office public health common data set use total resident population as the denominator ie YLL is given as a rate per 10000 of the total resident population. Although the numerator (the YLL) incorporates both age at death and number of deaths, the denominator is not sensitive to the age structure of the resident population. By including those aged 75 years and over the denominator includes those who are not at risk of a premature death.

\section{Methods}

AGE SENSITIVE DENOMINATORS

Three methods of incorporating age sensitive denominators are given below:

(i) Given that the YLL is calculated for all deaths under 75 years - that is no "credit" is given for those dying 75 years and above - it would be more accurate to represent YLL as a rate per 10000 resident population aged 0 to 74 years. Thus, the denominator is the population at risk of a premature death.

(ii) A more age sensitive denominator could be derived by applying the same calculation to the resident population, under 75 years of age, as to the numerator, to give the potential years of life (PYL) of the resident population if there were no premature deaths. Thus the denominator is the potential years of life of the population at risk. The calculation is as follows:

$$
\mathrm{PYL}=\Sigma(74 \cdot 5-\mathrm{p})^{*} \mathrm{~N}_{\mathrm{p}}
$$

where the sum is over ages 0 to 74 years; $p$ is age of person; $\mathrm{N}_{\mathrm{p}}$ is the resident population during the period under consideration at age p.

The numerator or years of life lost (YLL) could then be expressed as a ratio or rate of the potential years of life (PYL). Due to the relatively small size of the YLL compared with PYL a rate per 100000 is suggested.

(iii) Crude rates are of limited epidemiological value and standardisation techniques are frequently used to enable valid comparisons to be made: for example, the standardised mortality ratio (SMR) is widely used. The indirect method of standardisation used in the calculation of SMRs could be applied to YLL to obtain an expected YLL based 
Table 1 Deaths from all causes 1987-91

\begin{tabular}{|c|c|c|c|c|c|c|c|c|}
\hline & \multicolumn{2}{|c|}{$Y L L / 10000$ total pop } & \multicolumn{2}{|c|}{$Y L L / 10000$ pop $<75 y$} & \multicolumn{2}{|c|}{$Y L L / P Y L($ per 100000$)$} & \multicolumn{2}{|c|}{$S Y L L$ ratio } \\
\hline & Rate & Rank & Rate & Rank & Rate & Rank & Ratio & Rank \\
\hline $\begin{array}{l}\text { Males DHA: } \\
\text { Mid Glamorgan } \\
\text { Pembrokeshire } \\
\text { Gwent } \\
\text { West Glamorgan } \\
\text { Gwynedd } \\
\text { East Dyfed } \\
\text { Clwyd } \\
\text { Powys } \\
\text { South Glamorgan } \\
\text { Wales }\end{array}$ & $\begin{array}{l}939 \\
937 \\
913 \\
903 \\
882 \\
866 \\
862 \\
850 \\
820 \\
888\end{array}$ & $\begin{array}{l}1 \\
2 \\
3 \\
4 \\
5 \\
6 \\
7 \\
8 \\
9\end{array}$ & $\begin{array}{l}980 \\
983 \\
957 \\
950 \\
937 \\
918 \\
911 \\
902 \\
859 \\
934\end{array}$ & $\begin{array}{l}2 \\
1 \\
3 \\
4 \\
5 \\
6 \\
7 \\
8 \\
9\end{array}$ & $\begin{array}{l}239 \\
245 \\
236 \\
237 \\
232 \\
234 \\
225 \\
230 \\
206 \\
230\end{array}$ & $\begin{array}{l}2 \\
1 \\
4 \\
3 \\
6 \\
5 \\
8 \\
7 \\
9\end{array}$ & $\begin{array}{r}106 \\
104 \\
102 \\
100 \\
100 \\
95 \\
98 \\
94 \\
95 \\
100\end{array}$ & $\begin{array}{l}1 \\
2 \\
3 \\
4 \\
5 \\
7 \\
6 \\
9 \\
8\end{array}$ \\
\hline $\begin{array}{l}\text { Females DHA: } \\
\text { Mid Glamorgan } \\
\text { West Glamorgan } \\
\text { Gwent } \\
\text { East Dyfed } \\
\text { Pembrokeshire } \\
\text { South Glamorgan } \\
\text { Clwyd } \\
\text { Gwynedd } \\
\text { Powys } \\
\text { Wales }\end{array}$ & $\begin{array}{l}571 \\
552 \\
519 \\
508 \\
504 \\
494 \\
492 \\
490 \\
453 \\
519\end{array}$ & $\begin{array}{l}1 \\
2 \\
3 \\
4 \\
5 \\
6 \\
7 \\
8 \\
9\end{array}$ & $\begin{array}{l}621 \\
609 \\
565 \\
566 \\
550 \\
541 \\
546 \\
552 \\
502 \\
571\end{array}$ & $\begin{array}{l}1 \\
2 \\
4 \\
3 \\
6 \\
8 \\
7 \\
5 \\
9\end{array}$ & $\begin{array}{l}156 \\
158 \\
143 \\
149 \\
141 \\
135 \\
140 \\
145 \\
132 \\
146\end{array}$ & $\begin{array}{l}2 \\
1 \\
5 \\
3 \\
6 \\
8 \\
7 \\
4 \\
9\end{array}$ & $\begin{array}{r}110 \\
105 \\
99 \\
96 \\
97 \\
98 \\
96 \\
94 \\
85 \\
100\end{array}$ & $\begin{array}{l}1 \\
2 \\
3 \\
6 \\
5 \\
4 \\
7 \\
8 \\
9\end{array}$ \\
\hline
\end{tabular}

YLL = years of life lost; PYL = potential years of life; SYLL = standardised YLL.

Table 2 Deaths from all cancers 1987-91

\begin{tabular}{|c|c|c|c|c|c|c|c|c|}
\hline & \multicolumn{2}{|c|}{$Y L L / 10000$ total pop } & \multicolumn{2}{|c|}{$Y L L / 10000$ pop<75y } & \multicolumn{2}{|c|}{$Y L L / P Y L($ per 100000$)$} & \multicolumn{2}{|c|}{$S Y L L$ ratio } \\
\hline & Rate & Rank & Rate & Rank & Rate & Rank & Ratio & Rank \\
\hline $\begin{array}{l}\text { Males DHA: } \\
\text { Gwynedd } \\
\text { Gwent } \\
\text { West Glamorgan } \\
\text { Pembrokeshire } \\
\text { Clwyd } \\
\text { East Dyfed } \\
\text { Mid Glamorgan } \\
\text { South Glamorgan } \\
\text { Powys } \\
\text { Wales }\end{array}$ & $\begin{array}{l}234 \\
223 \\
222 \\
215 \\
215 \\
213 \\
212 \\
197 \\
175 \\
214\end{array}$ & $\begin{array}{l}1 \\
2 \\
3 \\
4 \\
5 \\
6 \\
7 \\
8 \\
9\end{array}$ & $\begin{array}{l}249 \\
233 \\
233 \\
226 \\
227 \\
225 \\
221 \\
206 \\
186 \\
225\end{array}$ & $\begin{array}{l}1 \\
2 \\
3 \\
5 \\
4 \\
6 \\
7 \\
8 \\
9\end{array}$ & $\begin{array}{l}62 \\
57 \\
58 \\
56 \\
56 \\
57 \\
54 \\
50 \\
47 \\
55\end{array}$ & $\begin{array}{l}1 \\
3 \\
2 \\
5 \\
6 \\
4 \\
7 \\
8 \\
9\end{array}$ & $\begin{array}{r}109 \\
104 \\
100 \\
98 \\
102 \\
93 \\
101 \\
97 \\
78 \\
100\end{array}$ & $\begin{array}{l}1 \\
2 \\
5 \\
6 \\
3 \\
8 \\
4 \\
7 \\
9\end{array}$ \\
\hline $\begin{array}{l}\text { Females DHA: } \\
\text { Gwynedd } \\
\text { West Glamorgan } \\
\text { Mid Glamorgan } \\
\text { Clwyd } \\
\text { Gwent } \\
\text { East Dyfed } \\
\text { Powys } \\
\text { South Glamorgan } \\
\text { Pembrokeshire } \\
\text { Wales }\end{array}$ & $\begin{array}{l}203 \\
199 \\
196 \\
195 \\
190 \\
189 \\
186 \\
180 \\
178 \\
192\end{array}$ & $\begin{array}{l}1 \\
2 \\
3 \\
4 \\
5 \\
6 \\
7 \\
8 \\
9\end{array}$ & $\begin{array}{l}229 \\
220 \\
213 \\
216 \\
207 \\
210 \\
206 \\
197 \\
194 \\
211\end{array}$ & $\begin{array}{l}1 \\
2 \\
4 \\
3 \\
6 \\
5 \\
7 \\
8 \\
9\end{array}$ & $\begin{array}{l}60 \\
57 \\
54 \\
56 \\
53 \\
55 \\
54 \\
49 \\
50 \\
54\end{array}$ & $\begin{array}{l}1 \\
2 \\
6 \\
3 \\
7 \\
4 \\
5 \\
9 \\
8\end{array}$ & $\begin{array}{r}104 \\
102 \\
103 \\
102 \\
99 \\
94 \\
93 \\
98 \\
91 \\
100\end{array}$ & $\begin{array}{l}1 \\
\mathbf{4} \\
2 \\
3 \\
5 \\
7 \\
8 \\
6 \\
9\end{array}$ \\
\hline
\end{tabular}

YLL = years of life lost; PYL = potential years of life; SYLL = standardised YLL.

on any standard population. The ratio of actual to expected YLL could then be presented as a standardised YLL ratio (SYLL).

The age sensitive denominators described above have been applied to mortality data for Wales for the period 1987-91. Indicators have been derived for males and females separately for deaths from all causes and also for deaths from all cancers. Comparisons are made between the nine DHAs in Wales; the DHA values for each of the indicators have been ranked in descending order.

The SYLL ratio has been derived using the Welsh population and YLL rates as the standard (that is Wales $=100$ ).

\section{Results}

Tables 1 and 2 provide the derived indicators for deaths from all causes and deaths from all cancers respectively. The YLL, expressed as a rate per 10000 total population, as currently used in public health common data sets, is given in addition to the indicators using age sensitive denominators. A comparison of the rank position of a district across the four indicators given shows the variation experienced relative to the other districts.

From table 1 for females, East Dyfed is ranked third, fourth, or sixth out of the nine districts, depending on which denominator is used. Similarly, also from table 1 for females, South Glamorgan is ranked fourth, sixth, or eighth, and Gwynedd fourth, fifth, or eighth.

From table 2 for males, Clwyd is ranked third, fourth, fifth, or sixth and East Dyfed fourth, sixth, or eighth out of the nine districts. Similarly from table 2 for females, Mid Glamorgan is ranked second, third, fourth, or sixth and East Dyfed fourth, fifth, sixth, or seventh out of the nine districts.

\section{Discussion}

The original objective of YLL was to compare the relative importance of different causes of 
death for a particular population; for this no denominator was required. However, YLL is now frequently used to make comparisons between authorities and is included in public health common data sets. That is, the objective for using YLL has changed, and to facilitate comparisons between authorities a denominator is required. Currently, the denominator used with YLL in public health common data sets is the total resident population. Consequently, although YLL (the numerator) incorporates both age at death and number of deaths, the denominator is not age sensitive and it includes those not at risk from premature death.

There are several ways of introducing an age sensitive denominator into the calculation, the simplest of which is to use the resident population aged under 75 years. This has the advantage of considering the same population in both numerator and denominator and ignoring those aged 75 and over - that is, the denominator represents the population at risk. A more exact measure, however, is to express the YLL over the potential years of life the population would have collectively lived if premature death had not occurred. This provides a denominator which takes account of the age distribution of the population in precisely the same way that the numerator does - that is, the potential years of life lost are expressed as a ratio of the potential years of life at risk.

Other perhaps more sophisticated methods are to standardise YLL using either the direct or indirect method. The results for SYLL using the indirect method alter the rank order of Welsh DHAs when compared with the other methods. This is perhaps not surprising as SYLL builds into the indicator the number of deaths expected, based on the standard population, as well as the age of death.

The calculation of potential years of life lost has an important place in public health common data sets, this could be enhanced by the use of a more appropriate denominator. This paper suggests that expressing potential years of life lost as a rate per 100000 potential years of life would be more appropriate. In addition to this standardised rates or ratios could be used.

My thanks to Donna Connolly and Hannah Lilley for typing the manuscript and to Dr W N Ritchie and Dr P R Alderson for constructive criticism.

1 Ortega A, Puig $M$. Influence of different upper age limits on the years of potential life lost index. Eur $\mathcal{f}$ Epidemiol 1992; the years of $875-7$.

2 Department of Health. Public health common data set 1991. London: Department of Health, 1991.

3 Welsh Office. Welsh public health common data set 1987-1991. Cardiff: Health Intelligence Unit, Welsh Health Common Services Authority, 1992.

4 Romeder JM, McWhinnie JR. Potential years of life lost between ages 1 and 70: an indicator of premature mortality for health planning. Int $\mathcal{f}$ Epidemiol 1977;6:143-51. 